\title{
Variation in the management of Kawasaki Disease in Australia and New Zealand: A survey of paediatricians.
}

\author{
Original Article
}

\section{Authors}

Ryan Lucas ${ }^{1,2}$

Peta Dennington ${ }^{3}$

Erica Wood ${ }^{4}$

Audrey Dionne $e^{5,6}$

Sarah D. de Ferranti ${ }^{5,6}$

Jane W. Newburger ${ }^{5,6}$

Nagib Dahdah ${ }^{7}$

Allen Cheng ${ }^{8}$

David Burgner ${ }^{9}$

Davinder Singh-Grewal ${ }^{1,2,10}$

1. Department of General Medicine - The Sydney Children's Hospitals Network Randwick and Westmead. Westmead, NSW, Australia.

2. Discipline of Child and Adolescent Health - The University of Sydney Faculty of Medicine and Health. Westmead, NSW, Australia.

This is the author manuscript accepted for publication and has undergone full peer review but has not been through the copyediting, typesetting, pagination and proofreading process, which may lead to differences between this version and the Version of Record. Please cite this article as doi: $10.1111 /$ jpc.15290

This article is protected by copyright. All rights reserved. 
3. Australian Red Cross Blood Service. Alexandria, NSW, Australia

4. Transfusion Research Unit - Monash University School of Public Health and Preventive Medicine. Melbourne, VIC, Australia.

5. Department of Cardiology - Boston Children’s Hospital. Boston, MA, USA.

6. Department of Pediatrics - Harvard Medical School. Boston, MA, USA.

7. Department of Pediatric Cardiology - University of Montreal. Montreal, Quebec, Canada.

8. Infectious Disease Epidemiology Unit - Monash University School of Public Health and Preventive Medicine. Melbourne, VIC, Australia.

9. Infection and Immunity Theme - Murdoch Children's Research Institute. Parkville, VIC, Australia.

10. School of Women's and Children's Health - University of New South Wales Faculty of Medicine. Sydney, NSW, Australia.

\section{Corresponding Author}

Dr Ryan Lucas

Children's Hospital Westmead Clinical School

Discipline of Child and Adolescent Health

The University of Sydney Faculty of Medicine and Health.

Hawksbury Road \& Hainsworth Street

Westmead, NSW, Australia 2145

Email:_ryan.lucas@health.nsw.gov.au

Phone: $\quad$ +61422734804

\section{Acknowledgements}

Local analysis was funded by a National Blood Sector Research and Development Grant (ID111) from the National Blood Authority, Australia. 


\section{Conflicts of Interest}

None.

\section{Abstract and Key Words}

\section{Aim}

To describe current management practices for Kawasaki Disease (KD) in Australia and New Zealand.

\section{Methods}

We performed a secondary analysis on the Australian and New Zealand responses to a large international survey of clinicians’ perspectives on KD diagnosis and management.

\section{Results}

There was general consensus among Australian and New Zealand clinicians regarding the indications for intravenous immunoglobulin (IVIG) and aspirin in management of acute KD. There was less consensus on the dose of these agents, the definition and management of treatment-resistant $\mathrm{KD}$, and the approach to long-term thromboprophylaxis.

\section{Conclusions}

Most clinicians use IVIG for primary treatment of KD. There is variation regarding other aspects of KD diagnosis and important management issues. Future studies should confirm whether this reported variation occurs in real-world practice and assess potential impacts on patient outcome.

\section{Key Words}

Kawasaki Disease, Mucocutaneous Lymph Node Syndrome, Intravenous Immunoglobulin, Aspirin 


\section{What is already known about this topic?}

1. Kawasaki Disease (KD) is an inflammatory condition of childhood that has become a leading cause of paediatric acquired heart disease in the developed world.

2. Intravenous immunoglobulin (IVIG) improves coronary artery outcomes in KD.

3. Guidelines for the management of KD vary around the world.

\section{What this paper adds.}

1. Clinicians almost unanimously reported prescribing IVIG for the primary therapy of acute $\mathrm{KD}$, albeit at varying dose.

2. There is disagreement about the dose of aspirin in acute KD.

3. There is a lack of consensus around important definitions, such as for IVIG resistant disease. 


\section{Introduction}

Kawasaki Disease (KD) is a systemic vasculitis that predominantly affects young children. The coronary arteries are particularly affected, and KD can result in morbidity ranging from mild and self-resolving coronary dilatation to permanent and life-threatening aneurysms. ${ }^{1}$ Intravenous immunoglobulin (IVIG) reduces the incidence of coronary artery lesions from $25 \%$ to $5 \%$ and it is the only intervention supported by evidence from randomised controlled trials. Aspirin has historically had two roles in KD: reducing inflammation and preventing thrombosis; evidence supporting either in $\mathrm{KD}$ is weak. ${ }^{4,5}$ Additional therapies (such as corticosteroids and biologics) are also used, though with less certainty as to their efficacy and role. ${ }^{6-8}$

KD that does not respond to primary therapy with IVIG ('IVIG resistance') is an important clinical entity, with non-responders at higher risk for coronary complications. ${ }^{9}$ Despite this, there is no consensus definition of IVIG resistance, and little evidence to inform management. Other areas of uncertainty include risk stratification of patients, adjunctive primary therapy, and the need for and duration of thromboprophylaxis. ${ }^{10}$

A recently published international survey of physicians' approach to $\mathrm{KD}$ diagnosis and management identified significant practice variation, particularly around adjunctive primary therapy and the definition and management of IVIG resistant disease. ${ }^{11}$ We undertook a secondary analysis of the Australian and New Zealand responses in this study to assess local areas of practice variation and to inform future local guidelines. 


\section{Methods}

We analysed responses from paediatricians in Australia and New Zealand participating in an international survey of clinicians' perspectives on KD diagnosis and management. ${ }^{11}$ The survey was hosted on SurveyMonkey and was distributed through professional and personal networks worldwide. Since the survey was not sent to a pre-determined number of clinicians, it was not possible to assess the response rate. Responses were recorded between January and August 2017. This sub-group analysis was planned in advance of results from the international survey having been analysed.

There were 42 questions in total (see supplementary material); respondents could choose not to answer questions. All responses were anonymous and providing demographic data was optional. Respondents reported their clinical speciality and were categorised as either Generalists (general paediatricians and those who reported no speciality) or Specialists (paediatric sub-specialities: cardiology, infectious disease, immunology, or rheumatology).

Statistical analyses (frequencies and proportions) were performed using Stata/IC 15.1 for Mac (StataCorp 2017. Stata Statistical Software: Release 15. College Station, Texas). Data are presented as proportions (percent), with non-responses subtracted from the denominator.

The international survey received ethical approval from Centre Hospitalier Universitaire Sainte-Justine in Montreal, Canada. This sub-analysis was granted exemption from ethical approval by the Sydney Children’s Hospitals Network. 


\section{Results}

\section{Respondents}

There were 108 respondents from Australia and New Zealand; descriptive statistics of respondents are provided in Table 1 . Sixty-nine percent (74/108) of respondents were general paediatricians and 81\% (88/108) reported managing fewer than 5 cases of KD per year.

\section{Diagnosis}

Respondents were asked how evidence for alternative or concurrent diagnoses would affect their certainty of the diagnosis of KD (in a child fulfilling the full clinical criteria as defined by the American Heart Association ${ }^{10}$ ). Clinicians retained the diagnosis of $\mathrm{KD}$ in the following clinical scenarios: lobar pneumonia on chest radiograph, 85\% (92 of 108); influenza on nasal swab PCR, 76\% (82 of 108); and toxic shock syndrome by clinical criteria, 51\% (55 of 108). (Supplementary Table 1)

Fifty-one percent (40 of 78) of general paediatricians reported that echocardiography was readily available at the time of diagnosis compared to 93\% (28 of30) of paediatric subspecialists. (Supplementary Table 2) When asked about the definition of giant coronary aneurysms 37\% (40 of 108) of respondents reported using absolute measurement of the internal diameter ( $\geq 8 \mathrm{~mm}$ ) and $44 \%$ (48 of 108) reported using normalised values (Z-score). (Supplementary Table 3)

\section{Primary Therapy}

Almost all respondents stated that they use IVIG as primary therapy for children with KD (9697\%, depending on coronary artery status at diagnosis). (Figure 1, Supplementary Tables 4-8) The majority of respondents used a dose of $2 \mathrm{~g} / \mathrm{kg}$, however almost $10 \%$ used a dose of $1 \mathrm{~g} / \mathrm{kg}$. (Figure 1, Supplementary Table 5)

Aspirin was widely prescribed at the time of diagnosis; only 11\% of respondents (11 of 104) indicated that they would not prescribe aspirin for children with normal coronary arteries at diagnosis. Respondents in New Zealand showed a general consensus in favour of moderatedose aspirin (30-50 mg/kg/day), regardless of the coronary artery status. There was less consensus among respondents in Australia: 48\% (38 of 80) used low-dose aspirin (3-5 $\mathrm{mg} / \mathrm{kg} /$ day) from diagnosis for children with normal coronary arteries, while 25\% each (20 of 80 ) used moderate-dose and high-dose (80-100 mg/kg/day) aspirin in these patients. Australian 
respondents were more likely to use high-dose aspirin as the coronary artery involvement worsened, with $40 \%$ (27 of 67) prescribing high-dose aspirin for children with giant aneurysms. (Figure 2, Supplementary Tables 9-11)

Use of corticosteroids as adjunctive primary therapy varied by coronary artery status at diagnosis. Four percent (4 of 104) of respondents selected corticosteroids for children with normal coronary arteries at diagnosis, compared with 12\% (12 of 98) and 21\% (19 of 89) for children with non-giant and giant aneurysms, respectively. Specialists were more likely than generalists to use corticosteroids. Biologic agents were infrequently used as primary adjunctive therapy. (Figure 1, Supplementary Tables 4-8)

\section{IVIG Resistance - Definition \& Management}

Respondents were asked how many hours after the end of IVIG infusion they would consider persistent or recrudescent fever to signify IVIG non-response. Fever at 24 hours was most commonly selected by respondents in Australia (59\% of Australians selected 24 hours, versus $27 \%$ of New Zealanders), whereas fever at 48 hours was most commonly selected by respondents in New Zealand (50\% of New Zealanders versus 20\% of Australians). (Figure 3, Supplementary Table 12)

Retreatment with IVIG was the most commonly selected therapy for the management of IVIG resistant KD (89-92\% of respondents, depending on coronary artery status at diagnosis). Corticosteroids were the second most commonly-selected therapy for IVIG-resistant KD (51$54 \%$ of respondents). Corticosteroids were commonly co-administered with the second dose of IVIG (about $90 \%$ of those who selected corticosteroids also selected IVIG). Intravenous corticosteroids were favoured over oral corticosteroids. Infliximab (a TNF- $\alpha$ inhibitor) was the most commonly selected biologic agent and was used more commonly by specialists than generalists. Thirteen percent of respondents selected infliximab for a child with resistant KD and giant coronary aneurysms. (Figure 1, Supplementary Tables 13-15)

\section{Thromboprophylaxis}

Low-dose aspirin was the most commonly selected agent for long-term thromboprophylaxis. The proportion of respondents who used aspirin varied with the severity of coronary artery involvement at diagnosis: eighteen percent of respondents (18 of 102) indicated that they would use long-term, low-dose aspirin for a child with normal coronary arteries at diagnosis, while $85 \%$ (76 of 89 ) would do so if there was persistent coronary artery dilatation. With 
increasing severity of coronary artery involvement, respondents were more likely to use alternative thromboprophylactic agents instead of, or in addition to, aspirin. For children with giant aneurysms, 57\% (49 of 86) indicated that they would use another thromboprophylactic agent long-term, either alone or in combination with aspirin. Of these, $61 \%$ (30 of 49) chose warfarin while $27 \%$ (13 of 49) and 22\% (11 of 49), respectively, chose a dual antiplatelet agent or low molecular-weight heparin.

\section{Discussion}

We describe the management of KD across Australia and New Zealand, performing a subgroup analysis of the survey originally reported by Dionne et al. ${ }^{11}$ That study described significant variation in the management of KD internationally; IVIG was widely accepted as first-line therapy, however there was variation around dose. Other areas of variation included the definition and management of IVIG resistant KD. We found consensus around the indications for IVIG but some variation around the dose used. The efficacy of IVIG in KD correlates with peak plasma immunoglobulin concentration, ${ }^{12}$ and evidence from randomised controlled trials recommends the higher dose of $2 \mathrm{~g} / \mathrm{kg}$. ${ }^{13}$ Current guidelines recommend a single dose of IVIG at $2 \mathrm{~g} / \mathrm{kg}$ per dose, given as a single infusion (Table 2). ${ }^{10,14,15}$

We also found significant variation around aspirin dosage in acute KD. Aspirin has dual proposed roles in KD management: inhibition of platelet activation at lower doses (3-5 $\mathrm{mg} / \mathrm{kg} /$ day) and anti-inflammatory effects at higher doses (>30 mg/kg/day). ${ }^{16}$ There are no convincing data to suggest efficacy of higher-dose aspirin compared with anti-platelet dose aspirin in preventing coronary aneurysms. $23 / 11 / 2020$ 11:58:00 AM There is currently significant disagreement among international guidelines around the approach to aspirin during the acute phase of KD (Table 2). The American Heart Association (AHA) guidelines suggest it is reasonable to use aspirin at either $30-50 \mathrm{mg} / \mathrm{kg} /$ day or $80-100 \mathrm{mg} / \mathrm{kg} /$ day until defervescence. ${ }^{10}$ The guidelines from Starship Hospital (Auckland, New Zealand) recommend aspirin at 30-50 $\mathrm{mg} / \mathrm{kg} /$ day, dropping to the lower anti-platelet dose after one week. ${ }^{15}$ Clinical Practice Guidelines from the Royal Children's Hospital (Melbourne), widely used in Australia, recommend aspirin at 3-5 mg/kg/day from diagnosis; this is based on the lack of evidence for the efficacy of higher-dose aspirin on coronary artery outcomes and considerable experience of low-dose aspirin for thromboprophylaxis. ${ }^{14}$ This seems to be an area of marked deviation from international standard practice: the international survey that produced these data showed 
that of 724 respondents only $13 \%$ used low dose aspirin in acute KD. ${ }^{17}$ In this context, it is not surprising to find lack of consensus in clinical practice. ${ }^{5}$

There was also considerable variation in practice with respect to management of IVIG resistance, which is inconsistently defined in the KD literature and in international guidelines (Table 2). Most definitions are based on the presence of ongoing inflammation after the first dose of IVIG - usually identified by the persistence or recrudescence of fever. ${ }^{10,14,15,18,19}$ Studies on the use of adjunctive anti-inflammatory agents have shown that earlier defervescence does not necessarily reduce the risk of coronary artery dilatation., ${ }^{4,6,20}$ Conversely, concurrent infection is a common finding in acute $\mathrm{KD}$, complicating the interpretation of ongoing fever. ${ }^{21} \mathrm{~A}$ fever-based definition of resistant disease may lack sensitivity and specificity. The treatment of resistant KD is an active area of clinical research, and there is a need to establish consensus on the definition to facilitate comparison across studies. $^{22}$

There is variation in the management of treatment-resistant KD. ${ }^{10}$ After a second dose of IVIG, corticosteroids were the most common adjunctive therapy. This is in keeping with the AHA guidelines, although evidence is limited for this approach. ${ }^{10,23}$ Infliximab was the most commonly used biologic agent for resistant KD. Infliximab has been studied as therapy for IVIG resistant KD; reductions in inflammatory cytokines and duration of fever have been shown; however, there is no evidence that this approach alters coronary outcomes. ${ }^{18}$ Given the relative low incidence of significant coronary artery damage in $\mathrm{KD}$, and the heterogeneity of treatment approaches in this patient group, these studies are likely underpowered to demonstrate a lack of benefit; further collaborative studies into the utility of infliximab in the treatment of $\mathrm{KD}$ are required. ${ }^{24}$

In keeping with the findings of the international survey, we found variation in the approach to ongoing thromboprophylaxis among respondents; however, our findings must be interpreted with caution. Ongoing anticoagulation is complex and highly individualised, based on both current coronary size and worst-ever coronary size. ${ }^{10}$ These decisions are typically made by cardiologists, who were relatively under-represented in this survey.

We acknowledge some key limitations of this study. Firstly, only a small number of paediatricians in Australia and New Zealand participated in the survey; the distribution of the survey was not systematic and may over-represent practice in tertiary institutions and major 
cities. Secondly, the questions were by necessity theoretical and assumed that coronary artery status was known at the time of diagnosis. This information is frequently unavailable when initial management decisions are made; however, assessing all possible scenarios of clinical uncertainty would have lengthened the survey to make the participant burden unacceptable. Thirdly, respondents were asked about scenarios that may fall outside their scope of practice (e.g. general paediatricians managing thromboprophylaxis children with giant coronary artery aneurysms) and were not given the option to indicate uncertainty; responses may not have reflected management decisions that are often taken after specialist multi-disciplinary discussions. We are currently undertaking prospective studies on KD in Australia to better describe these and other aspects of KD management.

\section{Conclusion}

We demonstrated consensus in clinical practice around the indications for IVIG and aspirin in the management of KD in Australia and New Zealand. There was lack of consensus on the dose of each agent and in the definition of and approach to the management of IVIG resistant KD. These findings should inform the development and dissemination of local practice guidelines. They also reinforce the ongoing need for international collaboration in KD research to develop and follow common definitions (such as the definition of IVIG resistance) and to clarify the roles of adjunctive therapies. 


\section{References}

1. Friedman KG, Gauvreau K, Hamaoka-Okamoto A, Tang A, Berry E, Tremoulet AH, et al. Coronary Artery Aneurysms in Kawasaki Disease: Risk Factors for Progressive Disease and Adverse Cardiac Events in the US Population. J Am Heart Assoc [Internet]. 2016 Aug 29 [cited 2019 Jan 27];5(9). Available from: https://www.ahajournals.org/doi/10.1161/JAHA.116.003289

2. Mori M, Miyamae T, Imagawa T, Katakura S, Kimura K, Yokota S. Meta-analysis of the results of intravenous gamma globulin treatment of coronary artery lesions in Kawasaki disease. Mod Rheumatol. 2004;14:7.

3. Oates-Whitehead RM, Baumer JH, Haines L, Love S, Maconochie IK, Gupta A, et al. Intravenous immunoglobulin for the treatment of Kawasaki disease in children. Cochrane Vascular Group, editor. Cochrane Database Syst Rev [Internet]. 2003 Oct 20 [cited 2019 Jan 27]; Available from: http://doi.wiley.com/10.1002/14651858.CD004000

4. Hsieh K-S, Weng K-P, Lin C-C, Huang T-C, Lee C-L, Huang S-M. Treatment of Acute Kawasaki Disease: Aspirin's Role in the Febrile Stage Revisited. Pediatrics. 2004 Dec 1;114(6):e689-93.

5. Dallaire F, Fortier-Morissette Z, Blais S, Dhanrajani A, Basodan D, Renaud C, et al. Aspirin Dose and Prevention of Coronary Abnormalities in Kawasaki Disease. Pediatrics. 2017 Jun;139(6):e20170098.

6. Kim GB, Yu JJ, Yoon KL, Jeong SI, Song YH, Han JW, et al. Medium- or Higher-Dose Acetylsalicylic Acid for Acute Kawasaki Disease and Patient Outcomes. J Pediatr. 2017 May;184(May):125-129.e1.

7. Wardle AJ, Connolly GM, Seager MJ, Tulloh RM. Corticosteroids for the treatment of Kawasaki disease in children. Cochrane Vascular Group, editor. Cochrane Database Syst Rev [Internet]. 2017 Jan 27 [cited 2019 Jan 27]; Available from: http://doi.wiley.com/10.1002/14651858.CD011188.pub2

8. Tremoulet AH, Jain S, Jaggi P, Jimenez-Fernandez S, Pancheri JM, Sun X, et al. Infliximab for intensification of primary therapy for Kawasaki disease: a phase 3 randomised, double-blind, placebo-controlled trial. The Lancet. 2014 May;383(9930):1731-8.

9. Eleftheriou D, Levin M, Shingadia D, Tulloh R, Klein N, Brogan P. Management of Kawasaki disease. Arch Dis Child. 2013;10.

10. McCrindle BW, Rowley AH, Newburger JW, Burns JC, Bolger AF, Gewitz M, et al. Diagnosis, Treatment, and Long-Term Management of Kawasaki Disease: A Scientific Statement for Health Professionals From the American Heart Association. Circulation. 2017;135(17):e927-e999.

11. Dionne A, Burgner D, De Ferranti S, Singh-Grewal D, Newburger J, Dahdah N. Variation in the management of Kawasaki disease. Arch Dis Child. 2019 Jun 13; archdischild-2019317191. 
12. Yamazaki-Nakashimada MA, Gámez-González LB, Murata C, Honda T, Yasukawa K, Hamada H. IgG levels in Kawasaki disease and its association with clinical outcomes. Clin Rheumatol [Internet]. 2018 Oct 20 [cited 2019 Jan 27]; Available from: http://link.springer.com/10.1007/s10067-018-4339-0

13. Durongpisitkul K, Gururaj VJ, Park JM, Martin CF. The Prevention of Coronary Artery Aneurysm in Kawasaki Disease A Meta-Analysis on the Efficacy of Aspirin and Immunoglobulin Treatment. Pediatrics. 1995;96(2).

14. The Royal Children's Hospital. Clinical Practice Guideline on Kawasaki Disease [Internet]. Melbourne, Australia; 2017 Aug [cited 2020 Jul 23]. Available from: https://www.rch.org.au/clinicalguide/guideline_index/Kawasaki_disease/

15. Webb R, Nicholson R, Wilson N. Kawasaki Disease [Internet]. Starship Child Health; 2019 Oct [cited 2020 Jul 25]. Available from: https://www.starship.org.nz/guidelines/kawasaki-disease/

16. Dhanrajani A, Yeung RSM. Revisiting the role of steroids and aspirin in the management of acute Kawasaki disease: Curr Opin Rheumatol. 2017 Sep;29(5):547-52.

17. Dionne A, de Ferranti S, Vanderpluym C, Burgner D, Singh-Grewal D, Newburger J, et al. Antithrombosis management of patients with Kawasaki Disease; results from an international survey. Can J Cardiol. 2018 Oct;34(10):S86-7.

18. Mori M, Hara T, Kikuchi M, Shimizu H, Miyamoto T, Iwashima S, et al. Infliximab versus intravenous immunoglobulin for refractory Kawasaki disease: a phase 3, randomized, open-label, active-controlled, parallel-group, multicenter trial. Sci Rep [Internet]. 2018 Dec [cited 2019 Jan 27];8(1). Available from: http://www.nature.com/articles/s41598-017-18387-7

19. Wallace CA, French JW, Kahn SJ, Sherry DD. Initial Intravenous Gammaglobulin Treatment Failure in Kawasaki Disease. Pediatrics. 2000;105(6):e78-e78.

20. Dionne A, Burns JC, Dahdah N, Tremoulet AH, Gauvreau K, de Ferranti SD, et al. Treatment Intensification in Patients With Kawasaki Disease and Coronary Aneurysm at Diagnosis. Pediatrics. 2019 May 2;e20183341.

21. Joshi AV, Jones KD, Buckley A-M, Coren ME, Kampmann B. Kawasaki disease coincident with influenza A H1N1/09 infection: Kawasaki disease with H1N1/09 infection. Pediatr Int. 2011 Feb;53(1):e1-2.

22. Dionne A, Le C-K, Poupart S, Autmizguine J, Meloche-Dumas L, Turgeon J, et al. Profile of resistance to IVIG treatment in patients with Kawasaki disease and concomitant infection. Bayry J, editor. PLOS ONE. 2018 Oct 17;13(10):e0206001.

23. Miura M, Tamame T, Naganuma T, Chinen S, Matsuoka M, Ohki H. Steroid pulse therapy for Kawasaki disease unresponsive to additional immunoglobulin therapy. Paediatr Child Health. 2011 Oct;16(8):479-84.

24. Levin M, Burgner D. Treatment of Kawasaki disease with anti-TNF antibodies. The Lancet. 2014 May;383(9930):1700-3. 


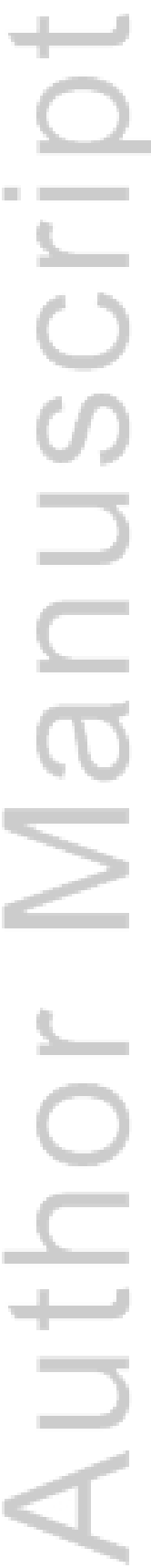


Table 1: Descriptive Statistics of Survey Respondents in Australia and New Zealand 
Table 2. Summary of Recommendations from International Kawasaki Disease Management Guidelines

A full comparison of available guidelines is available in Supplementary Table 1. 
Figure 1: Reported Therapies used in the Treatment of Kawasaki Disease in Australia and New Zealand, by Specialisation

Therapies selected by general paediatricians (panel A.) and paediatric sub-specialists (panel B.) for the first-line management of acute Kawasaki Disease. The category 'Other' includes anti-TNF $\alpha$ agents.

Therapies selected by general paediatricians (panel C.) and paediatric sub-specialist (panel D.) for the treatment of IVIG-resistant Kawasaki Disease. The category 'Biologics' includes infliximab, etanercept, anakinra, and canakinumab; the category 'Other' includes cyclosporine.

Results are provided in detail in the Supplementary Results. 
Figure 2: Aspirin Dose used in the Febrile Phase of Kawasaki Disease in Australia and New Zealand, by Country

Dose of aspirin selected by respondents in Australia (panel A.) and New Zealand (panel B.) for treatment of Kawasaki Disease during the febrile phase.

Results are provided in detail in the Supplementary Results. 
Figure 3: Time after the First Dose of IVIG at which IVIG-Resistanct Kawasaki Disease is Diagnosed by the Presence of Fever in Australia and New Zealand, by Country

IVIG-resistant Kawasaki Disease is defined as persistence or recrudescence of fever after the first dose of IVIG; the time at which this diagnosis is made varies.

Hours at which the presence of fever indicates failure to respond to treatment, as reported by respondents in Australia (panel A.) and New Zeland (panel B.).

Results are provided in detail in the Supplementary Results. 


\section{First-Line Therapies Used in Kawasaki Disease}
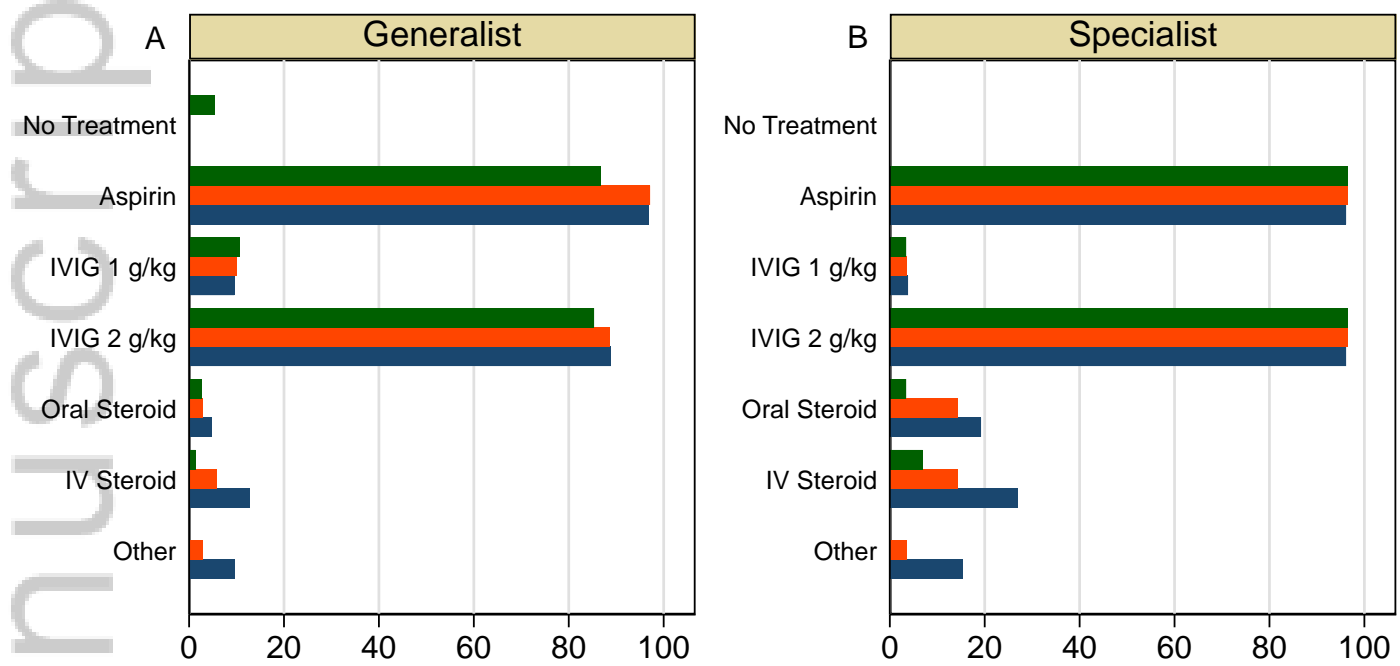

\section{Second-Line Therapies Used in Kawasaki Disease}
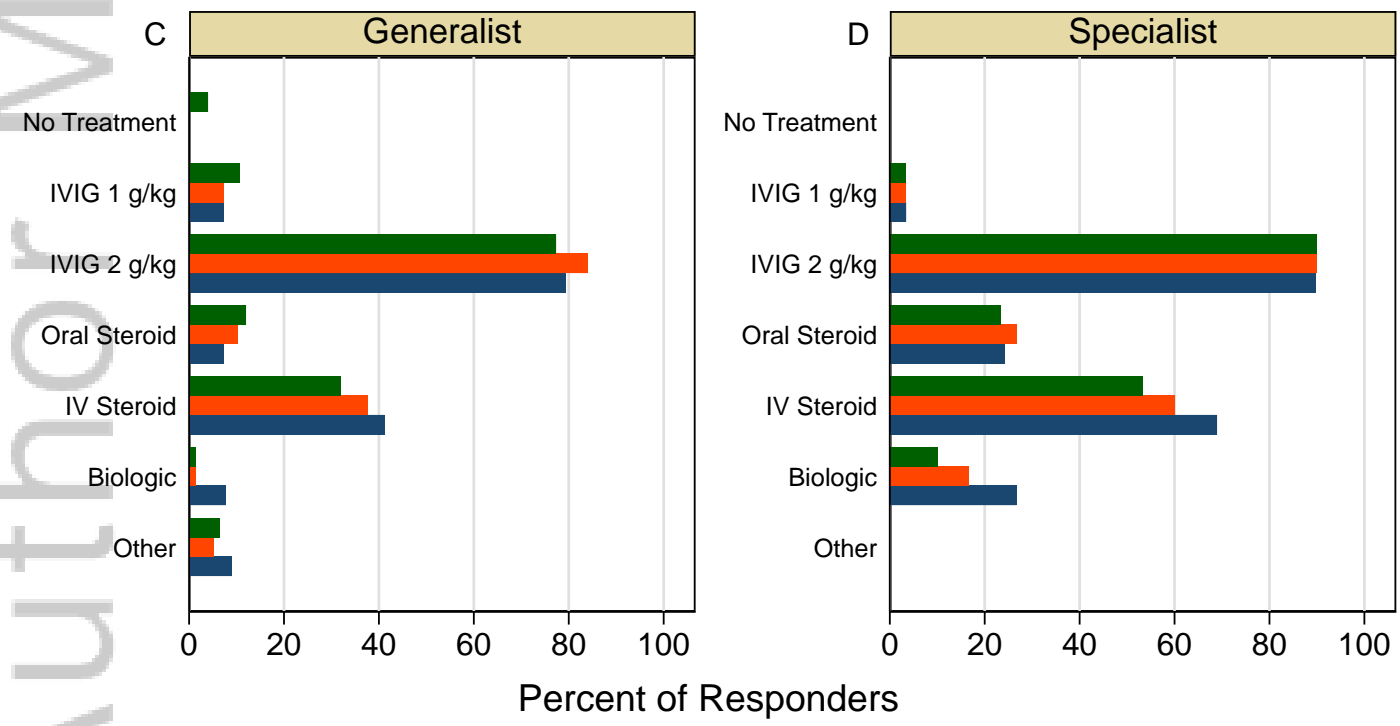

Percent of Responders 


\section{Use of Aspirin in Acute Kawasaki Disease}

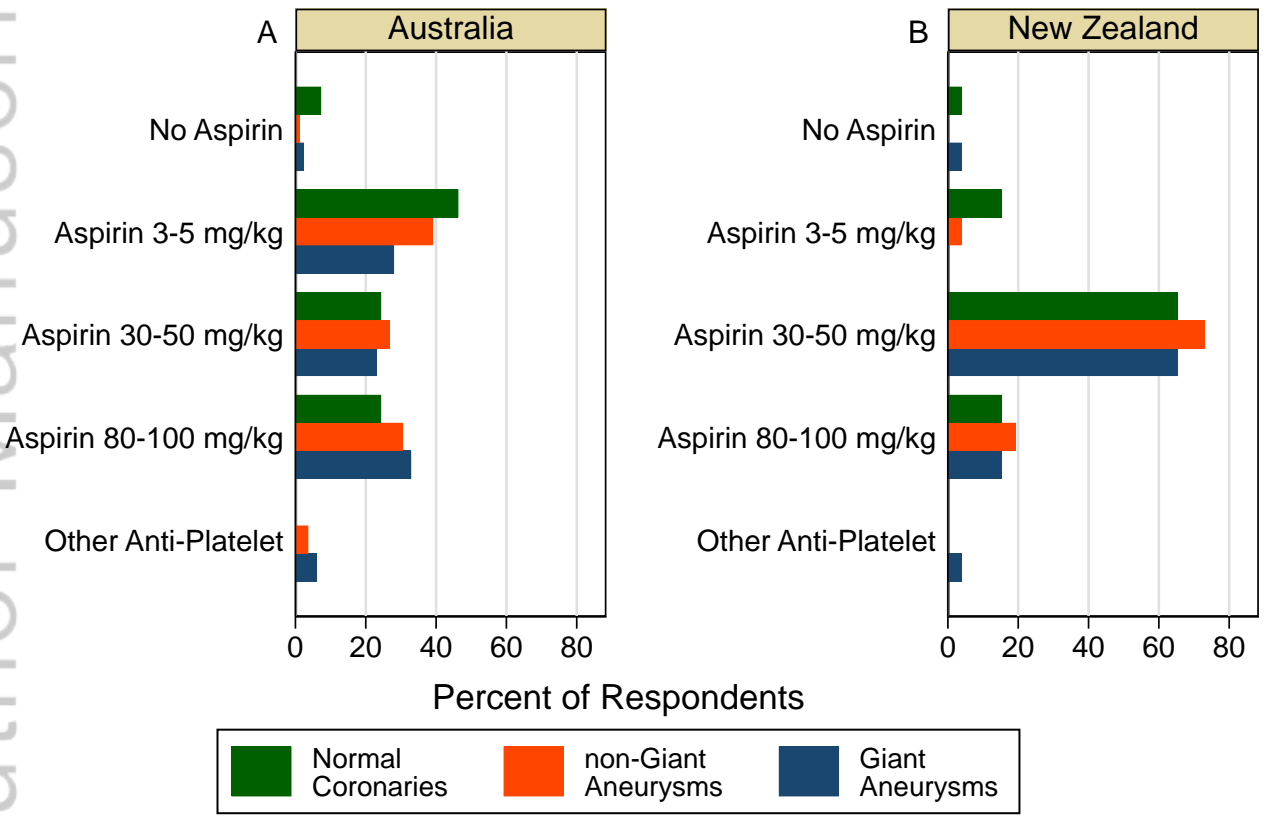


Definition of IVIG Resistance in Kawasaki Disease: Time from End of IVIG Infusion to Fever Recurrence

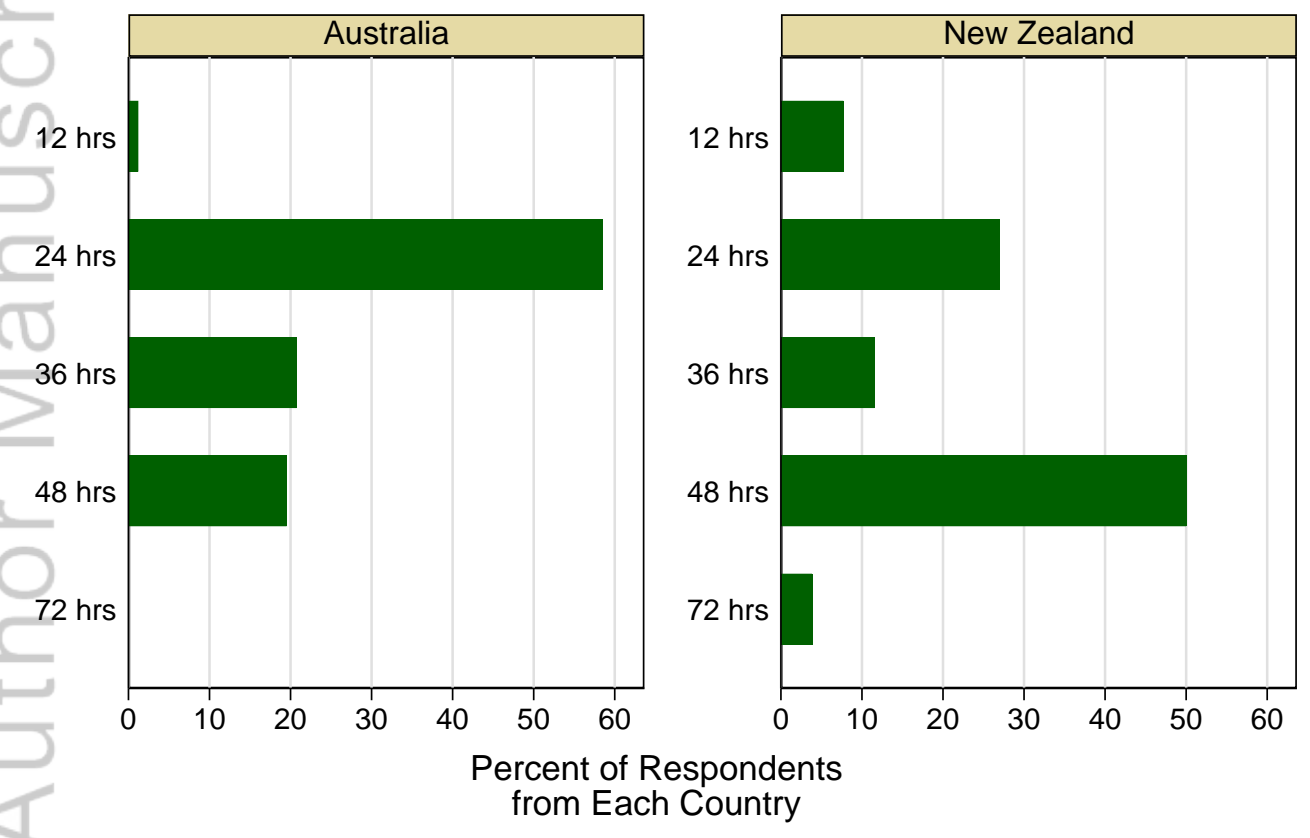


Table 1: Descriptive statistics of survey respondents in Australia and New Zealand.

\begin{tabular}{|c|c|c|c|c|c|c|}
\hline & \multicolumn{2}{|c|}{ Australia } & \multicolumn{2}{|c|}{ New Zealand } & \multicolumn{2}{|c|}{ Total } \\
\hline & No. & $(\%)$ & No. & $(\%)$ & No. & $(\%)$ \\
\hline \multicolumn{7}{|l|}{ Gender } \\
\hline Female & 45 & (55) & 14 & (54) & 59 & (55) \\
\hline Male & 36 & (44) & 12 & (46) & 48 & (44) \\
\hline Unknown & 1 & (1) & 0 & (0) & 1 & (1) \\
\hline Total & 82 & $(100)$ & 26 & $(100)$ & 108 & $(100)$ \\
\hline \multicolumn{7}{|l|}{ Speciality } \\
\hline General Paediatrics & 56 & (68) & 18 & (69) & 74 & (69) \\
\hline Cardiology & 4 & (5) & 4 & (15) & 8 & (7) \\
\hline Infectious Diseases & 9 & (11) & 2 & (8) & 11 & (10) \\
\hline Immunology / Rheumatology & 9 & (11) & 2 & (8) & 11 & (10) \\
\hline None & 4 & (5) & 0 & (0) & 4 & (4) \\
\hline Total & 82 & $(100)$ & 26 & $(100)$ & 108 & $(100)$ \\
\hline \multicolumn{7}{|l|}{ Years of Practice } \\
\hline$\leq 5$ years & 20 & (24) & 3 & (12) & 23 & (21) \\
\hline $6-10$ years & 18 & (22) & 7 & (27) & 25 & (23) \\
\hline $11-15$ years & 10 & (12) & 3 & (12) & 13 & (12) \\
\hline 16-20 years & 15 & (18) & 6 & (23) & 21 & (19) \\
\hline$>20$ years & 19 & (23) & 7 & (27) & 26 & (24) \\
\hline Total & 82 & $(100)$ & 26 & $(100)$ & 108 & $(100)$ \\
\hline \multicolumn{7}{|l|}{ KD Patients in Last Year } \\
\hline$<5$ & 64 & (78) & 24 & (92) & 88 & (81) \\
\hline$\geq 5$ & 18 & (22) & 2 & (8) & 20 & (19) \\
\hline Total & 82 & (100) & 26 & (100) & 108 & (100) \\
\hline
\end{tabular}


Table 2: Comparison of Kawasaki Disease Management Guidelines.

\begin{tabular}{|c|c|c|c|c|}
\hline Region & $\begin{array}{l}\text { IVIG } \\
\text { (g/kg) }\end{array}$ & $\begin{array}{l}\text { Aspirin } \\
\text { (mg/kg/day) }\end{array}$ & $\begin{array}{l}\text { Definition of Resistance } \\
\text { (hours from treatment) }\end{array}$ & $\begin{array}{l}\text { Treatment of IVIG } \\
\text { Resistance }\end{array}$ \\
\hline Australia & 2 & $3-5$ & 36 & $\begin{array}{l}\text { 1. IVIG } \\
\text { 2. Corticosteroids }\end{array}$ \\
\hline Europe & 2 & $\begin{array}{l}30-50 \text { initially, } \\
\text { then 3-5 }\end{array}$ & 36 or 48 & $\begin{array}{l}\text { 1. IVIG } \\
\text { 2. Corticosteroids } \\
\text { 3. Biologics }\end{array}$ \\
\hline Japan & 2 & $\begin{array}{l}\text { 30-50 initially, } \\
\text { then 3-5 }\end{array}$ & 24 & $\begin{array}{l}\text { 1. IVIG } \\
\text { 2. Corticosteroids } \\
\text { 3. Biologics }\end{array}$ \\
\hline New Zealand & 2 & $\begin{array}{l}\text { 30-50 initially, } \\
\text { then 3-5 }\end{array}$ & $48-72$ & $\begin{array}{l}\text { 1. IVIG } \\
\text { 2. Corticosteroids } \\
\text { 3. Biologics }\end{array}$ \\
\hline North America & 2 & $\begin{array}{l}30-50 \text { or } 80-100 \text { initially, } \\
\text { then } 3-5\end{array}$ & 24 or 36 & $\begin{array}{l}\text { 1. IVIG } \\
\text { 2. Biologics } \\
\text { 3. Corticosteroids }\end{array}$ \\
\hline United Kingdom & 2 & $\begin{array}{l}30-50 \text { or } 80-100 \text { initially, } \\
\text { then } 3-5\end{array}$ & $36-48$ & $\begin{array}{l}\text { 1. IVIG } \\
\text { 2. Corticosteroids } \\
\text { 3. Biologics }\end{array}$ \\
\hline
\end{tabular}

Drawn from publicly available clinical practice guidelines. 


\title{
Variation in the management of Kawasaki Disease in Australia and New Zealand: A survey of paediatricians.
}

\author{
Original Article
}

\author{
Authors \\ Ryan Lucas ${ }^{1,2}$ \\ Peta Dennington ${ }^{3}$ \\ Erica Wood ${ }^{4}$ \\ Audrey Dionne ${ }^{5,6}$ \\ Sarah D. de Ferranti ${ }^{5,6}$ \\ Jane W. Newburger ${ }^{5,6}$ \\ Nagib Dahdah ${ }^{7}$ \\ Allen Cheng ${ }^{8}$ \\ David Burgner ${ }^{9}$ \\ Davinder Singh-Grewal ${ }^{1,2,10}$
}

1. Department of General Medicine - The Sydney Children's Hospitals Network Randwick and Westmead. Westmead, NSW, Australia.

2. Discipline of Child and Adolescent Health - The University of Sydney Faculty of Medicine and Health. Westmead, NSW, Australia.

3. Australian Red Cross Blood Service. Alexandria, NSW, Australia

4. Transfusion Research Unit - Monash University School of Public Health and Preventive Medicine. Melbourne, VIC, Australia.

5. Department of Cardiology - Boston Children’s Hospital. Boston, MA, USA.

6. Department of Pediatrics - Harvard Medical School. Boston, MA, USA.

7. Department of Pediatric Cardiology - University of Montreal. Montreal, Quebec, Canada.

8. Infectious Disease Epidemiology Unit - Monash University School of Public Health and Preventive Medicine. Melbourne, VIC, Australia.

9. Infection and Immunity Theme - Murdoch Children's Research Institute. Parkville, VIC, Australia. 
10. School of Women's and Children's Health - University of New South Wales Faculty of Medicine. Sydney, NSW, Australia.

\section{Corresponding Author}

Dr Ryan Lucas

Children's Hospital Westmead Clinical School

Discipline of Child and Adolescent Health

The University of Sydney Faculty of Medicine and Health.

Hawksbury Road \& Hainsworth Street

Westmead, NSW, Australia 2145

Email:_ryan.lucas@health.nsw.gov.au

Phone: +61422734804

\section{Acknowledgements}

Local analysis was funded by a National Blood Sector Research and Development Grant (ID111) from the National Blood Authority, Australia.

\section{Conflicts of Interest}

None. 


\section{University Library}

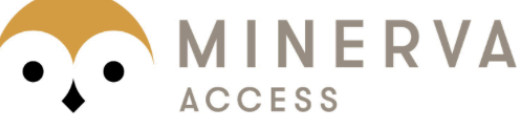

A gateway to Melbourne's research publications

Minerva Access is the Institutional Repository of The University of Melbourne

\section{Author/s:}

Lucas, R;Dennington, P;Wood, E;Dionne, A;de Ferranti, SD;Newburger, JW;Dahdah,

$\mathrm{N}$;Cheng, A;Burgner, D;Singh-Grewal, D

Title:

Variation in the management of Kawasaki disease in Australia and New Zealand: A survey of paediatricians

Date:

2020-12-09

\section{Citation:}

Lucas, R., Dennington, P., Wood, E., Dionne, A., de Ferranti, S. D., Newburger, J. W., Dahdah, N., Cheng, A., Burgner, D. \& Singh-Grewal, D. (2020). Variation in the management of Kawasaki disease in Australia and New Zealand: A survey of paediatricians. JOURNAL OF PAEDIATRICS AND CHILD HEALTH, 57 (5), pp.646-652. https://doi.org/10.1111/ jpc. 15290.

Persistent Link:

http://hdl.handle.net/11343/298038 